\title{
Treatment of inoperable carcinoma of the bronchus by megavoltage $x$ rays
}

\author{
THOMAS J. DEELEY ANDS. PADAM SINGH \\ From the Hammersmith Hospital, London, W.12
}

\begin{abstract}
The techniques of treatment of carcinoma of the bronchus using 8 million volt $x$ rays are described. In a group of inoperable cases of carcinoma of the bronchus a three-year survival rate of $10 \%$ was obtained with squamous lesions, and in anaplastic and oat-cell lesions the three-year survival rate was $4 \%$. The factors affecting the prognosis are described and also the palliation achieved. The immediate reactions and the late complications of treatment are described and are no more severe than with orthovoltage $x$-ray therapy.
\end{abstract}

Malignant disease of the bronchus is usually treated by surgery if the condition is operable. Unfortunately, only a small proportion of the patients who develop the disease are suitable for radical surgery and in only a number of these can the tumour and the associated lymph nodes be removed. For the large proportion of patients with inoperable growths radiotherapy offers the only chance of controlling the disease. The results of treatment of lesions of the bronchus with orthovoltage $x$-ray apparatus are not good and the reported five-year survival rates have varied from $1 \%$ to $4 \%$ (Hilton and Pilcher, 1955; Smithers, 1955 ; Schulz, 1957 ; Shanks, 1959).

With the introduction of supervoltage apparatus tumours in the chest can be treated more effectively than with the conventional apparatus in the $200-250 \mathrm{kV}$ range. The advantages of supervoltage apparatus are:

(1) A higher dose of radiation can be delivered to deeply placed tumours because of the greater energy and penetration of the beam.

(2) The skin receives only a proportion of the tumour dose because the build-up of scattered electrons takes place at a depth in tissue. With 8 million volts the maximum build-up is $2 \mathrm{~cm}$. deep to the skin. With cobalt-60 machines the maximum dose is at $0.5 \mathrm{~cm}$.

(3) The differential absorption of $x$ rays in bone at this voltage is considerably less than with orthovoltage apparatus. Consequently less damage is caused to bone and the screening effect of bone is reduced.

'Present address: Christian Medical College Hospital, Vellore, Madras State. Indea
(4) Because the secondary scatter radiation is mainly in a forward direction the resultant beam is well collimated and there is reduced scatter outside the main beam with less damage to the adjacent normal tissues.

(5) Many supervoltage machines have a high dose rate which allows treatment to be given in 2 or 3 minutes, compared with 15 or 20 minutes by conventional $x$-ray machines.

Because of these advantages it seemed that the chance of tumour ablation with supervoltage radiation was more likely than with the lower voltages previously used. Morrison, Deeley, and Cleland (1963) reported a controlled clinical trial to compare the treatment of operable carcinoma $\underset{x}{\simeq}$ of the bronchus by surgery and by radical super- $\frac{0}{7}$ voltage radiotherapy. Patients selected for the trial were under 70 years of age, in fairly good general health, and able to undergo a pneumonectomy. There was no spread of tumour outside the chest $\frac{\text { ? }}{3}$ and no evidence of gross mediastinal involvement. $>$ The diagnosis of carcinoma was confirmed in all cases histologically. In a series of 58 patients, $28 \mathrm{~N}$ received radical radiotherapy to the chest, and in $\sigma$ 30 patients a radical surgical removal of the $\tilde{O}$ tumour and the associated lymph nodes was per- $\mathbb{W}$ formed. In the patients treated by surgery there 0 was a four-year survival rate of $23 \%$ and in those 6

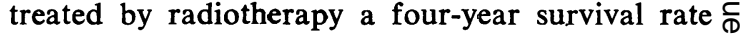
of $7 \%$. These differences are statistically signifi- $\stackrel{0}{+}$ cant. They further showed that the greatest 0 difference in survival rate occurred in the ${ }_{0}$ squamous lesions, there being no difference in the $\mathbb{\triangle}$ anaplastic lesions. The authors concluded that $\mathbb{D}$ 'under the conditions in which this trial has been 
conducted it appears that surgery is the better method of treatment for operable cases of squamous carcinoma of the lung'. In operable anaplastic lesions it appears that the results of radical radiotherapy are as good as those of surgery. In oat-celled lesions, a M.R.C. Working Party (1966) concluded that radiotherapy was preferable to surgery.

\section{INOPERABLE CARCINOMA}

Patients with carcinoma of the bronchus, which is inoperable because of either advanced local disease or poor respiratory reserve, may be considered for a radical course of supervoltage $x$-ray therapy aimed at ablating the disease, if the patient is still in fairly good health and has no evidence that the disease has spread outside the chest. The presence of a blood-stained pleural effusion or a pleural effusion with malignant cells, where spread of the disease has possibly occurred throughout the whole area of the pleura, is considered a contraindication to radical $x$-ray treatment. Where there is evidence of acute infection in the chest the patient is usually treated with the appropriate antibiotic before starting a course of radiotherapy. Tuberculosis of the lung has not been considered a contraindication to treatment even if it is in the field of radiation. Where the tuberculous lesion is believed to be acute or quiescent or where the sputum has been positive, the patient is started on antituberculous drugs which are continued for some months after the completion of $x$-ray therapy. Where the tuberculous disease appears to be healed antituberculous drugs are not given.

THE PATIENTS The patients reviewed here were referred for radiotherapy because the condition was inoperable. They were considered suitable for a radical course of radiotherapy because they were still in reasonably good general health, with no clinical evidence that the disease had spread outside the chest. The clinical diagnosis was confirmed in the majority of the patients by histological or cytological examination. All cases without histological proof of carcinoma were reviewed with the referring physician or surgeon and accepted for radical treatment only if there was good clinical, radiographic, or bronchoscopic evidence of a primary bronchial carcinoma.

There were 478 males $(93.2 \%)$ and 35 females $(6.8 \%)$, and the average age of the patients was $59 \cdot 5$ years.

TREATMENT Treatment has been given by means of an 8 million volt linear accelerator. Two nonopposed fields have been used to irradiate the

FIGURE. Isodose distribution using two non-opposed fields with wedge filters. The figures represent the percentage of the peak dose. The dose on the skin at the entry part of the field is on $15 \%$ of the peak dose. The tumour is represented by hatching.

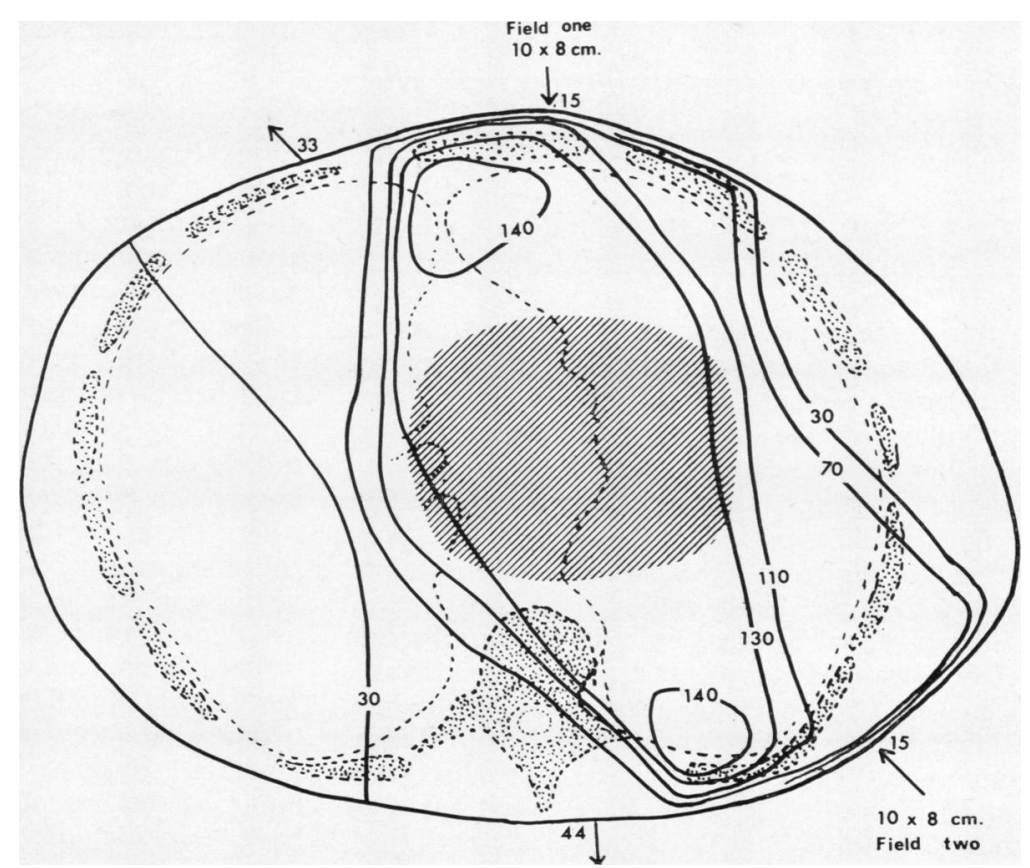


lesion in the thorax, one straight-on anterior field and a posterior field applied obliquely to avoid irradiating the spinal cord. The use of wedge filters has given a uniform tumour dose over the whole area. The Figure shows an isodose distribution using two wedge filters. The volume treated has included the opaque area seen on the postero-anterior and lateral radiographs and a surrounding zone of apparently normal lung. The hilum of the lung and the mediastinal node areas have been included in the fields of radiation in all cases even if there was no clinical or radiological evidence that there were metastases to these areas. The tumour doses given have varied according to the histology of the primary lesion. A tumour dose of 4,500 rads was given in 20 treatments in four weeks for squamous lesions. In anaplastic and oat-cell lesions, where usually much larger fields were required, a tumour dose of 3,600 rads was given in 20 treatments in four weeks.

\section{RESULTS OF TREATMENT}

Survival rates Five hundred and thirteen patients received a radical course of treatment to the bronchus. The survival rates are shown in Table I. These results have been calculated using an actuarial method of analysis.

\section{T A B L E I}

SURVIVAL RATES IN 513 CASES

\begin{tabular}{cc:c} 
& & Per Cent Survival \\
\hline 1 year & $\ldots$ & 36 \\
2 years & $\ldots$ & 15 \\
3 years & $\ldots$ & 8 \\
4 years & $\cdots$ & 7 \\
5 years & $\cdots$ & 6 \\
\hline
\end{tabular}

After three years the risk of dying from the disease appears to be quite small, and it appears that a three-year survival rate is a fairly satisfactory index of the value of the treatment in controlling this disease.

Before starting treatment, wherever possible histological diagnosis of the tumour has been obtained either from a biopsy specimen obtained at bronchoscopy, from cytology of the sputum, or, in peripheral lesions, by drill biopsy through the chest wall. However, in a proportion of cases ( 83 out of $513,16 \%$ ) no histology was obtained and the diagnosis was made entirely on clinical examination. Table II compares the three-year survival rates for the main histological types of tumours.
T A B L E I I

SURVIVAL ACCORDING TO HISTOLOGY

\begin{tabular}{l|c|c|c|c|c}
\hline & Squamous & $\begin{array}{c}\text { Anaplastic } \\
\text { and } \\
\text { Oat-cell }\end{array}$ & $\begin{array}{c}\text { Adeno- } \\
\text { carcinoma }\end{array}$ & $\begin{array}{c}\text { Not } \\
\text { Known }\end{array}$ & Total \\
\hline $\begin{array}{l}\text { No. of cases . } \\
\text { 3-year survival }\end{array}$ & $266 \%$ & $\begin{array}{c}153 \\
4 \%\end{array}$ & $11 \%$ & $83 \%$ & 513 \\
\hline
\end{tabular}

It will be seen that the three-year survival rate $\stackrel{\vec{x}}{x}$ is worse for anaplastic lesions than for the other $\mathrm{N}$ two types. The survival rate of the patients where on the diagnosis was clinical only is of the same or order as in the cases where there was histological $N$ verification.

The effect of the site of the primary lesion on the three-year survival rate for squamous and $z$ anaplastic lesions is shown in Table III.

T A B L E I I I

SITE OF THE PRIMARY LESION

\begin{tabular}{|c|c|c|c|c|}
\hline & & $\begin{array}{c}\text { Main } \\
\text { Bronchus }\end{array}$ & $\begin{array}{l}\text { Upper and } \\
\text { Middle } \\
\text { Lobe } \\
\text { Bronchi }\end{array}$ & $\begin{array}{c}\text { Lower Lobe } \\
\text { Bronchus }\end{array}$ \\
\hline $\begin{array}{l}\text { Squamous } \\
\text { No. of cases . . } \\
\text { 3-year survival }\end{array}$ & $\begin{array}{l}\ldots \\
\ldots\end{array}$ & $\begin{array}{l}58 \\
16 \%\end{array}$ & $\begin{array}{l}131 \\
13 \%\end{array}$ & $\begin{array}{l}77 \\
2 \%\end{array}$ \\
\hline $\begin{array}{l}\text { Anaplastic } \\
\text { No. of cases } \\
\text { 3-year survival }\end{array}$ & $\begin{array}{l}\ldots \\
\ldots\end{array}$ & $\begin{array}{l}45 \\
3 \%\end{array}$ & $\begin{array}{l}68 \\
7 \%\end{array}$ & $\begin{array}{l}40 \\
0 \%\end{array}$ \\
\hline
\end{tabular}

It will be seen that in squamous lesions the survival rate for upper and main bronchus lesions is about the same, but lower lobe lesions have a $-\dot{\sigma}$ poorer prognosis. In anaplastic lesions the main 3 bronchus tumours and the lower lobe lesions both have a poor survival rate.

The prognosis after treatment is dependent on the presence of mediastinal node involvement. Evidence of mediastinal node involvement may be clinical, as shown by recurrent laryngeal palsy, radiological, as shown by paralysis of the dia- $/ 0$ phragm or by a mediastinal mass, bronchoscopic, N where there is widening of the carina, or as seen $N$ at thoracotomy. Table IV shows the effect of $\omega$ mediastinal node involvement on the two main histological types.

The differences shown in this Table are not $\mathscr{D}$ statistically significant, but the results are slightly better where the mediastinum is not involved. It must be remembered that in all cases of carci- $\mathbb{D}$ noma of the bronchus the mediastinal node areas $\frac{O}{\mathbb{}}$ have been included in the field of radiation. 
T A B L E I V

EFFECT OF MEDIASTINAL INVOLVEMENT ON THE MAIN HISTOLOGICAL TYPES

\begin{tabular}{lccc}
\hline & $\begin{array}{c}\text { Mediastinum } \\
\text { not Involved }\end{array}$ & $\begin{array}{c}\text { Mediastinum } \\
\text { Involved }\end{array}$ \\
\hline $\begin{array}{l}\text { Squamous } \\
\text { No. of cases } \ldots\end{array}$ & $\ldots$ & 158 & 108 \\
$\begin{array}{l}\text { 3-year survival } \\
\text { Anaplastic } \\
\begin{array}{l}\text { No. of cases } \\
\text { 3-year survival }\end{array}\end{array}$ & $\cdots$ & $11 \%$ & $7 \%$ \\
\hline
\end{tabular}

Palliation of symptoms Although the survival rates after treatment are not good, many patients obtain considerable relief of symptoms as a result of the radical treatment. Table $\mathrm{V}$ shows the effect of radiation on the four main presenting symptoms, haemoptysis, cough, dyspnoea, and pain.

T A B L E V

EFFECTS OF RADIATION ON THE PRESENTING SYMPTOMS

\begin{tabular}{|c|c|c|c|c|c|}
\hline & \multirow{2}{*}{$\begin{array}{c}\text { No. } \\
\text { of } \\
\text { Cases }\end{array}$} & \multirow{2}{*}{$\begin{array}{l}\text { Response } \\
\text { not } \\
\text { Known }\end{array}$} & \multicolumn{3}{|c|}{$\%$ Where Response known } \\
\hline & & & Improved & No Change| & Worse \\
\hline $\begin{array}{l}\text { Haemoptysis } \\
\text { Cough } \quad . \\
\text { Dyspnoea } \\
\text { Pain } \quad \text {.. }\end{array}$ & $\begin{array}{l}134 \\
334 \\
224 \\
112\end{array}$ & $\begin{array}{l}2 \\
9 \\
8 \\
4\end{array}$ & $\begin{array}{l}97 \\
65 \\
71 \\
75\end{array}$ & $\begin{array}{r}3 \\
31 \\
26 \\
23\end{array}$ & $\begin{array}{l}0 \\
4 \\
3 \\
2\end{array}$ \\
\hline
\end{tabular}

The palliation has been assessed as 'improved', which includes total disappearance or partial relief of the symptom, 'no change', and 'worse'. In a small number of patients the response was not known.

It will be seen that in the majority of patients with haemoptysis the symptom was improved. Haemoptysis usually disappeared during treatment. The remaining symptoms, cough, dyspnoea, and pain, were relieved in about two-thirds to three-quarters of the patients and in only a small percentage were the symptoms made worse as a result of the treatment. There was no difference in the response of the symptoms for the different histological types.

Reactions The reactions occurring within a few weeks of radiation are due to the direct effects of radiation on either the oesophagus or the normal lung tissue.

Oesophageal reactions Radiation causes irritation of the oesophageal mucosa, with the formation of a mucous membrane reaction similar to that found on the mucosa of the mouth and throat. The patient complains of dysphagia, which increases in severity as the treatment progresses. Initially, dysphagia is present only with hot foods or drinks, but it may become worse so that the patient can drink only fluids, and may, in a small number of patients, become so severe that food cannot be taken at all and treatment has to be discontinued. Fifty-six per cent of patients receiving a radical course of radiotherapy for a carcinoma of the bronchus complained of some degree of dysphagia, usually occurring about the third week of the treatment.

In only $2 \%$ of patients was the dysphagia severe enough to necessitate stopping the treatment. When dysphagia develops it has been our practice to stop the treatment for a few days until the symptoms subside, and then the patient is often able to continue to the full planned dose.

Radiation effects on the lung The effects of irradiation on the lung in patients treated by an 8 $\mathrm{MeV}$ linear accelerator were reported by Deeley (1960). It is possible to distinguish two different radiological pictures: (1) an increase in the size and density of the opacity in the treated lung; and (2) evidence of lung fibrosis and shrinkage. The opacity may be hazy in appearance, but may consist of patchy areas of consolidation which may coalesce to form dense shadows. This corresponds to the initial stage of reaction in the lung tissue, and histological section of the lung at this time shows reaction in the lung parenchyma, filling of the alveolar spaces with macrophages and exudate, and thickening of the alveolar walls with lymphocytic infiltration of the interstitial tissues.

These changes are followed later by evidence of fibrosis and shrinkage as shown on the radiographs by movement of the mediastinal contents, elevation of the diaphragm, and contraction of the ribs on the affected side. In all patients treated there was some evidence of lung shrinkage at about 12 months. Histological section of the lung at this stage shows fibrosis of the lung tissue with complete loss of tissue structure.

The differential diagnosis of radiation effects is between pulmonary tuberculosis, infection, and residual tumour in the lung, and it is often difficult to differentiate between the different diseases. Deeley (1960) showed that the effects of radiation on the lung with supervoltage radiation were no more severe than those experienced in the lungs of patients treated to a radical tumour dose with orthovoltage therapy.

The fibrosed lung is very prone to infection. It is often not possible to identify the affecting 
organisms and usually a broad-spectrum antibiotic has to be given.

\section{DISCUSSION}

The use of supervoltage radiations in the treatment of inoperable carcinoma of the bronchus has brought about a small improvement in the survival rate. The five-year survival rate for 176 cases of inoperable carcinoma of the bronchus treated at this centre with $240 \mathrm{kV} x$ rays was $1 \%$ (Morrison and Deeley, 1960). With supervoltage therapy the survival rate at five years is $6 \%$ (Table I). If these results are broken down according to the histology then (1) the three-year survival rate of squamous lesions was $4.5 \%$ for $240 \mathrm{kV}$ therapy and $10 \%$ for $8 \mathrm{MeV}$ therapy (Table II); and (2) the three-year survival rate for anaplastic lesions was $0 \%$ for $240 \mathrm{kV}$ therapy and $6 \%$ for $8 \mathrm{MeV}$ therapy (Table III). This improvement is probably due to the improved physical properties of the supervoltage $x$-ray beam. Similar findings have been observed by other workers. Guttmann (1961) compared the results of carcinoma of the bronchus treated by 2 million volt $x$ rays and also cobalt-60 radiation with the results from a 250 $\mathrm{kV}$ machine (orthovoltage) and found that supervoltage therapy achieved subjective and objective results far superior to those obtained with orthovoltage.

\section{REFERENCES}

Deeley, T. J. (1960). The effects of radiation on the lungs in the treatment of carcinoma of the bronchus. Clin. Radiol., 11, 33.

Guttmann, R. J. (1961). Comparison of three different methods of external irradiation, and their results, in the treatment of inoperable carcinoma of the lung. Radiology, 76, 83 .

Hilton, G., and Pilcher, R. S. (1955). In British Practice in Radiotherapy. Ed. Carling, E. R., Windeyer, B. W., and Smithers, D. W. p. 258. Butterworth, London.

Medical Research Council Working Party '19:i6). Comparative trial N of surgery and radiotherapy for the primary treatment of small-
celled or oat-celled carcinoma of the bronchus. Lancet, 2, 979.

Morrison, R., and Deeley, T. J. $(19 ; n)$ Inoperable cancer of the bronchus treated by $\mathrm{m}$.gavoltage x-ray therapy. Ibid., 2, 618 .

the bronchus. A clinical trial to compare surgery and supervoltage radiotherapy. Ibid., 1, 683 .

Schulz, M. D. (1957). The results of radiotherapy in cancer of the lung Radiology, 69, 494.

Shanks, W. (1959). Malignant tumous of the lung and pleura. In Cancer, Vol. 5, p. 316. Edited by Raven, R. W. Butterworth London.

Smithers, D. W. (1955). Carcinoma of the bronchus. A radiotherapy viewpoint. J. Fac. Radiol. (Lond.), 6, 174. 